\title{
Study the Relationship between Chronic Inflammation and DNA Changes in Children on Regular Hemodialysis
}

\author{
Maha Zein El-Abden ${ }^{1}$, Manal Abdel Salam ${ }^{1}$, Soheir Saad Korraa ${ }^{2}$, \\ Heba Allah Moawad ${ }^{1}$ \\ 1Department of Pediatrics, Faculty of Medicine, Al-Azhar University, Cairo, Egypt \\ 2Department of Molecular Biology, National Center for Radiation Research and Technology- Atomic \\ Energy Authority, Cairo, Egypt \\ Corresponding author: Manal Abdel Salam, Tel.: 01006337676,Email: manal24969@gmail.com
}

\begin{abstract}
:
Background and Aim of the Work: Inflammation is a common feature in chronic kidney disease (CKD), especially enhanced in end stage renal disease patients on hemodialysis (HD). Under inflammatory conditions, reactive oxygen species (ROS) and reactive nitrogen species (RNS) are generated from inflammatory and epithelial cells and result in DNA damage. In this study we assess DNA fragmentation in children with chronic kidney disease on regular hemodialysis sand detect its relation with some of the inflammatory markers.
\end{abstract}

Material and Methods: The study included 40 children with CKD on regular hemodialysis (HD), and they were selected from the hemodialysis unit of Al-Zahraa hospital, Al-Azhar University, during the period from April 2016 to January 2018. Another group of 40 apparently healthy children, matches age and sex with patients group as a controls. Serum level of C-reactive protein (CRP), tumor necrosis factor (TNF- $\alpha$ ) and DNA fragmentation assay in the same line with routine investigations were assessed for both groups

Results: Children on regular hemodialysis have significantly higher CRP and TNF- $\alpha$ serum levels compared to their controls, it was $(27.25 \pm 4.64 \mathrm{mg} / \mathrm{L}),(10.04 \pm 1.90 \mathrm{ng} / \mathrm{ml})$ and $(1.86 \pm 0.59 \mathrm{mg} / \mathrm{L})(2.75 \pm 0.56 \mathrm{ng} / \mathrm{ml})$ respectively, $(\mathrm{P}<0.001)$. There was a significant increase in DNA fragmentation in patients group $(1.51 \pm 0.31)$ compared to the controls $(0.54 \pm 0.21)$ with $(\mathrm{P}<0.001)$. DNA damage was present in $(92 \%)$ of the study patients. There were significant positive correlations between DNA fragmentation and serum level of CRP, TNF- $\alpha$, body mass index and dialysis duration.

Conclusion: Almost children on hemodialysis are exposed to DNA damage with significant association with inflammatory markers, duration of hemodialysis and BMI.

Keywords: CKD, DNA damage, hemodialysis, TNF- $\alpha$

INTRODUCTION: Chronic kidney disease (CKD) is a progressive condition marked by deteriorating kidney function over time. The early stages of CKD are manifested by kidney damage and are generally asymptomatic, whereas more advanced stages of CKD require treatment of uraemia and its complications and ultimately renal replacement therapy when end-stage renal disease (ESRD) is reached ${ }^{(1)}$.

Patients with chronic kidney disease (CKD) have high incidence rates of cardiovascular disease and cancer. Several factors contribute to these conditions, uraemia, micro-inflammation and oxidative stress [free radicals, reactive oxygen species (ROS), etc] are the main mechanisms underlying this phenomenon ${ }^{(2)}$.

Inflammation is a common feature in CKD, especially enhanced in ESRD patients on hemodialysis
HD). This chronic inflammatory state seems to contribute to aggravate kidney dysfunction and favor the occurrence of comorbidities and the risk of mortality (3).

Chronic inflammation can itself lead to increased oxidative stress in advances renal disease, with malnutrition, chronic volume overload and autonomic dysfunction as some factors implicated in the increased inflammatory state seen in renal impairment. Studies have observed association between many mediators of inflammation such as CRP, IL-6, TNF- $\alpha$ and renal dysfunction, in chronic kidney disease patients, the polymorphnuclear neutrophils are activated and myeloperoxidase is generated, triggering reactive oxygen species activation ${ }^{(4)}$.

Extensive genetic damage in patients with $\mathrm{CKD}$, possibly due to accumulation of uremic 
toxins, oxidative stress and other endogenous substances with genotoxic properties ${ }^{(5)}$.

Impairment of DNA damage repair and increased chromosome damage in patients with $\mathrm{KD}$ may be caused by the uraemic state as well as by chronic inflammation linked to increased formation of reactive oxygen species. ${ }^{(6)}$

Patients with CKD have an elevated risk for developing cancer ${ }^{(7)}$. DNA lesions may induce mutations in oncogenes and tumour-suppressor genes that may lead to malignancies if mutagenicity is not mitigated by repair mechanisms ${ }^{(8)}$.

AIM OF THE WORK: The aim of this study was to assess DNA fragmentation in a children on regular hemodilaysis and detect its relation with some of the inflammatory markers.

MATERIALS AND METHODS: This is cross sectional comparative study, conducted during the period from April 2016 to January 2018. The sample included 40 children recruited from nephrology \& hamodialysis unit of $\mathrm{Al}$ zahraa hospital, Al Azhar University. The investigation was carried out on patients who attended the pediatric hemodialysis unit during the period of the study. They were on regular hemodialysis more than three months at the time of the study, for 4 hours/ setting, 3 times weekly, with low-flux polysulphone dialyzer by 4008 Fresenius machine. They were 23 females and 17 males, their ages ranged from 5-18 years. A group of 40 healthy children, matched age and sex with patients group served as controls. Children with acute infection, tumors or on chemotherapy and with other chronic diseases were excluded from the study. The patients were subjected to full history taking including etiology, onset of $\mathrm{CKD}$, duration of hemodialysis and laboratory investigations. Informed consent was obtained from the participating parents in adherence with the guidelines of the ethical committee of Al Zahraa hospital, Al-Azhar University, Cairo, Egypt. This study was conducted with participation of Pediatric Department and the National Center for Radiation Research and Technology Atomic Energy Authority.

\section{Sampling}

Venous blood samples $(5 \mathrm{ml})$ were withdrawn from each subject before dialysis and divided into 3 specimens:

1) A specimen $(2 \mathrm{ml})$ was put on EDTA tubes for complete blood picture.
2) A specimen (about $3 \mathrm{ml}$ ) of the samples was put in a plain tubes were left to clot and sera were separated without delay for the biochemical parameters (urea, creatinine, triglyceride, cholesterol, and total protein) to be done on the same day.

3) Another portions of the serum sample stored frozen at $-20 \mathrm{c}$ after careful labeling till the time of assay of:

- DNA fragmentation assay.

- Tumor necrosis factor (TNF- $\alpha$ ) and C-reactive protein (CRP) assay by ELISA.

\section{DNA fragmentation assay}

This is done according to the method of Ioannou and Chen (1996) ${ }^{(9)}$ and colorimetricaly using polyethyelene glycol 8000 to separate fragmented DNA from intact one.

\section{Principle:}

DNA fragments in the range of $20-300 \mathrm{~kb}$ are early sign of cellular apoptosis. The technique is based on hypotonic lysis of blood cells followed by the selective precipitation of un-fragmented, highmolecular weight DNA by polyethylene glycol (PEG) 8000.

\section{Statistics}

Data were collected revised, coded and entered to the statistical package for social science (IBM SPSS) version 20. Spearman correlation coefficients were used to assess the relation between two studied parameters in the same group. $\mathrm{P}>0.05$ : Non significant. $\mathrm{P}<0.05$ : Significant. $\mathrm{P}<0.01$ : Highly significant.

RESULTS: The results illustrated in Table 1 showed a significant increase in the serum level of urea, creatinine, triglyceride, and cholesterol in dialysis group than healthy controls, while there was a significant decrease in the serum level of total protein in dialysis group compared to their controls

Table 2 demonstrated a significant increase in CRP and TNF- $\alpha$ serum levels and an increase in DNA fragmentation in dialysis children compared to their controls.

Figure 1 showed that $92.5 \%$ of participating subjects have DNA breakage among the study patients.

Inspection of figures 2-5 demonstrated that, DNA fragmentation is positively correlated with CRP, TNF- $\alpha$, BMI and duration of hemodialysis respectively. 
Table (1): Comparison between patients and control group regarding laboratory data

\begin{tabular}{|l|c|c|c|c|}
\hline \multicolumn{1}{|c|}{ Laboratory data } & $\begin{array}{c}\text { Patients group (N=40) } \\
\text { Mean+SD }\end{array}$ & $\begin{array}{c}\text { Controls group } \\
\text { (N=40) } \\
\text { Mean } \pm \text { SD }\end{array}$ & t-test & p-value \\
\hline Age (years) & $11.58 \pm 4.67$ & $9.79 \pm 3.07$ & 2.096 & 0.062 \\
\hline z-score for BMI & $-0.20 \pm 1.37$ & $0.20 \pm 0.26$ & 3.195 & 0.065 \\
\hline Urea (mg/dl) & $78.66 \pm 3.38$ & $13.38 \pm 3.97$ & 303.108 & 0.001 \\
\hline Creatinine (mg/dl) & $7.79 \pm 2.27$ & $0.82 \pm 0.16$ & 374.213 & 0.001 \\
\hline Total Protein (mg/dl) & $6.11 \pm 0.78$ & $6.46 \pm 0.58$ & 5.216 & 0.025 \\
\hline Serum Albumin (mg/dl) & $4.03 \pm 0.36$ & $4.12 \pm 0.43$ & 1.128 & 0.291 \\
\hline TG (mg/dl) & $171.93 \pm 27.22$ & $71.73 \pm 8.64$ & 369.113 & 0.001 \\
\hline Cholesterol (mg/dl) & $226.05 \pm 49.21$ & $154.73 \pm 9.77$ & 80.849 & 0.001 \\
\hline
\end{tabular}

Table (2): Comparison between patients and control group regarding serum level of CRP, TNF- $\alpha$ and DNA fragmentation.

\begin{tabular}{|l|c|c|c|c|}
\hline \multicolumn{1}{|c|}{ Variables } & $\begin{array}{c}\text { Patients group }(\mathbf{N}=\mathbf{4 0}) \\
\text { Mean } \pm \text { SD }\end{array}$ & $\begin{array}{c}\text { Controls group }(\mathbf{N}=40) \\
\text { Mean+SD }\end{array}$ & t-test & p-value \\
\hline CRP $(\mathbf{m g} / \mathbf{L})$ & $27.25 \pm 4.64$ & $1.86 \pm 0.59$ & 119.367 & 0.001 \\
\hline TNF- $\alpha(\mathbf{n g} / \mathbf{m l})$ & $10.04 \pm 1.90$ & $2.75 \pm 0.56$ & 544.366 & 0.001 \\
\hline $\begin{array}{l}\text { DNA } \\
\text { Fragmentation }\end{array}$ & $1.51 \pm 0.31$ & $0.54 \pm 0.01$ & 275.768 & 0.001 \\
\cline { 2 - 5 }
\end{tabular}

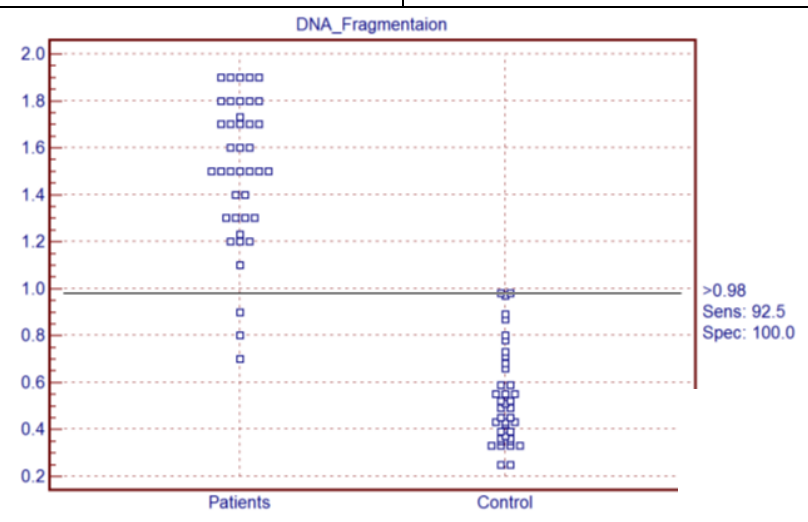

Figure (1): Demonstrate that $92.5 \%$ of study patients have DNA breakage.

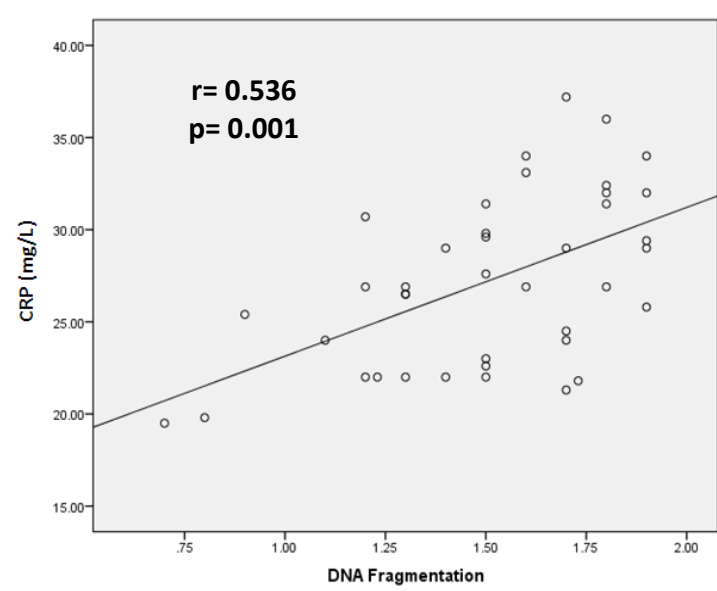

Figure (2): Correlation between DNA fragmentation and CRP serum level.

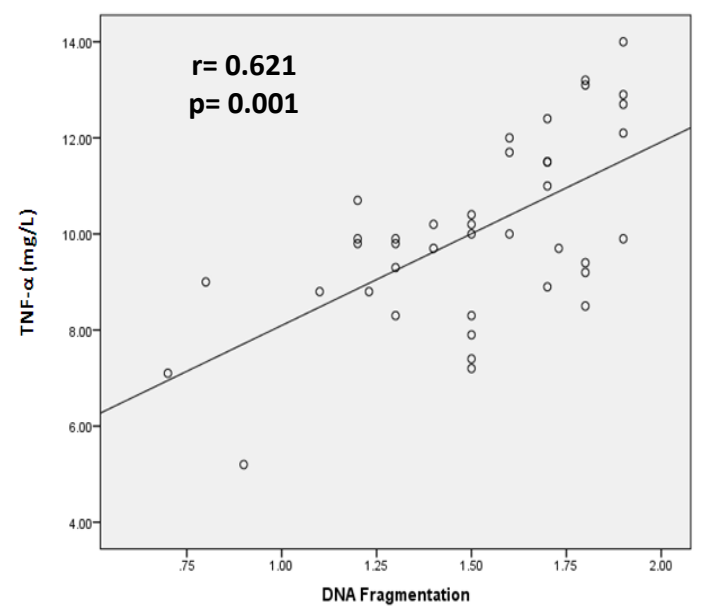

Figure (3): Correlation between DNA fragmentation and TNF- $\alpha$ serum level. 


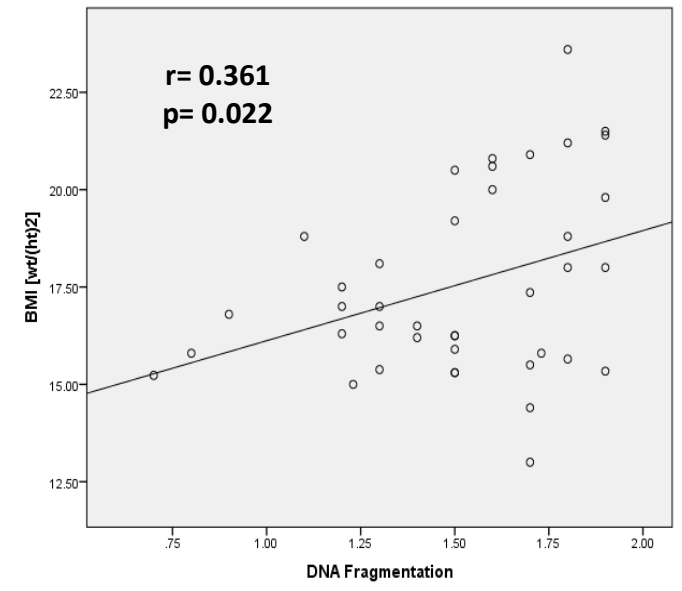

Figure (4): Correlation between DNA fragmentation and BMI.

DISCUSSION: We are interested in studying and measure the burden of genomic damage in children who are kept on hemodialysis and detect its correlation with some parameters related to pathology particularly the inflammatory biomarkers.

The role of dialysis on genomic damage is conflicting. Most of the DNA damage caused by oxidative stress can be repaired by various repair systems present in the cells, some damage might escape the repair machinery or the repair may be exhausted when too many lesions occur ${ }^{(10)}$.

The present study showed differences in the level of the inflammatory biomarkers CRP and TNF- $\alpha$ in children on regular hemodialysis compared to control subjects. Rangel-López et al. ${ }^{(5)}$ reported similar finding. Chronic inflammation directly correlates with the glomerular filtration rate (GFR) in CKD and culminates in dialysis patients, where extracorporeal factors, such as impurities in dialysis water, microbiological quality of dialysate and bioincompatible factors in the dialysis circuit play an additional role ${ }^{(11)}$. Other studies had similarly demonstrated that children with varying degrees of kidney dysfunction had higher inflammatory markers as CRP and TNF- $\alpha$ than the general population ${ }^{(12)}$.

We analyzed the DNA fragmentation by chemical method which is probably more sensitive in determining the percentage of apoptosis in cultured cells than direct scoring of apoptotic nuclei ${ }^{(9)}$.

Our study showed that cell damaged DNA is increased in children on hemodialysis with significant correlation to $\mathrm{CRP}, \mathrm{TNF}-\alpha$ and Wbcs. Under inflammatory conditions, reactive oxygen

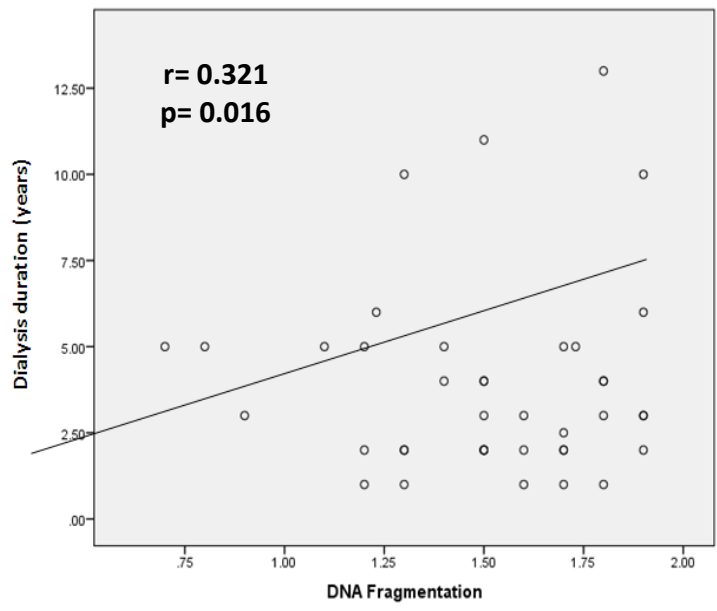

Figure (5): Correlation between DNA fragmentation and dialysis duration.

species (ROS) and reactive nitrogen species (RNS) are generated from inflammatory and epithelial cells and result in DNA damage ${ }^{(13)}$. HD treatment seems to contribute per se to enhance inflammation and, thus, it may also favor genetic damage and the associated complications ${ }^{(14)}$. In agreement with the present study, Ohnishi et al. ${ }^{(15)}$, Hooten et al. ${ }^{(16)}$, and Schupp et al. ${ }^{(17)}$ reported that, patients with chronic kidney disease have high levels of genomic damage.

In contradictory to the present findings, Rangel-López et al. ${ }^{(5)}$ could not find a difference between matched controls and hemodialysis patients regarding the DNA breakage. An explanation might be improvement of the hemodialysis procedures and the concomitant pharmaco-therapy over time ${ }^{(18-19)}$ and may also related to the method of DNA breakage detection.

The effects of time on genomic damage in patients with HD is controversial, in the present study, duration of dialysis treatment and level of DNA damage were found to be positively correlated. These results are consistent with the report of Moffitt et al. ${ }^{(20)}$; Roth et al. ${ }^{(21)}$; Zachara et $\boldsymbol{a l} .{ }^{(22)}$, in that DNA fragmentation has significant positive correlation with long duration of dialysis. However, Aykanat et al. ${ }^{(23)}$ and Ersson et al. ${ }^{(24)}$, reported no significant correlation, On the other hand, there was a negative association between time on dialysis and genetic damage ${ }^{(7)}$. Moreover daily dialysis patients showed a significantly lower degree of genomic damage, suggesting that the amelioration in the uraemic state would reduce the degree of genomic damage ${ }^{(24)}$. Corredor et al. ${ }^{(25)}$, reported that online hemodiafiltration (OL-HDF) reduced the levels of DNA damage in these patients, as this approach provides a reduction of inflammation and oxidative stress 
It is not surprising, but interesting to find a significant positive correlation between DNA damage and BMI in children on hemodialysis. Most of children with CKD are malnourished; malnutrition and protein-energy wasting, common in CKD, may also contribute to the inflammatory condition of CKD patients ${ }^{(26)}$. We observed significant increase in the serum level of cholesterol and triglyceride in hemodialysis children, BMI has been identified as a distinct risk factor for dyslipidaemia in the paediatric CKD population ${ }^{(27,28)}$, lipid disorders, enhanced oxidative stress and inflammation ${ }^{(29,30)}$.

CONCLUSION: We have shown that, almost children on hemodialysis are more prone to DNA damage as we detected that $92 \%$ of them had DNA damage with significant positive correlation to the inflammatory status, duration of hemodialysis and BMI.

We recommend that pharma-cological interventions and optimization of hemodialysis modalities aiming to reduce or increasing removal of inflammatory mediators. Further studies are needed to evaluate the long-term effects of various anti-inflammatory treatments and new hemodialysis modality strategies on genomic damage in children on hemodialysis

LIMITATIONS OF THE STUDY: Some limitation of the study include, low number of the study population, and their heterogeneity due to different CKD and frequent pharmacological treatments.

\section{REFERENCES:}

1. Weiner DE (2007): Causes and consequences of chronic kidney disease: implications for managed health care. J. Manag. Care Pharm., 13: S1- S9.

2. Fragedaki E, Nebel M, Schupp N, et al (2005): Genomic damage and circulating $A G E$ levels in patients undergoing daily versus standard haemodialysis. Nephrol Dial Transplant, 20:1936-1943.

3. Muslimovic A, Rasic S, Tulumovic D, Hasanspahic S, Rebic D (2015): Inflammatory markers and procoagulants in chronic renal disease stages 1-4. Medical Archives, 69:307-310.

4. Kao MP, Ang DS, Pall AA, Struthers AD (2010): Oxidative stress in renal dysfunction: mechanisms, clinical sequelae and therapeutic options. J Hum Hypertens, 24(1):1-8.
5. Rangel-López A, Paniagua-Medina ME, Urbán-Reyes M et al. (2013): Genetic damage in patients with chronic kidney disease, peritoneal dialysis and haemodialysis: a comparative study. Mutagenesis, 28(2):219225.

6. Himmelfarb J (2009): Uremic toxicity, oxidative stress, and hemodialysis as renal replacement therapy. Semin. Dial., 22:636643.

7. Maisonneuve $\mathbf{P}$, Agodoa L, Gellert $\mathbf{R}$ et al. (1999): Cancer in patients on dialysis for endstage renal disease: an international collaborative study. Lancet, 35: 493-499.

8. Stopper H, Meysen T, Bockenforde A et al. (1999): Increased genomic damage in lymphocytes of patients before and after longterm maintenance hemodialysis therapy. Am. J. Kidney Dis., 344:334-337.

9. Ioannou Y and Chen F (1996): Quantification of DNA fragmentation in apoptosis. Nucleic Acid Research, 24: 992-998.

10. Dey S, Maiti AK, Hegde ML et al. (2012): Increased risk of lung cancer associated with a functionally impaired polymorphic variant of the human DNA glycosylase NEIL2. DNA Repair, 11(6): 570-578.

11. Neirynck N, Glorieux G, Schepers E et al. (2015): Pro-inflammatory cytokines and leukocyte oxidative burst in chronic kidney disease. Nephrol Dial Transplant., 30: 943951.

12. Adejumo O, Okaka E, Okwuonu C et al. (2016): Serum C-reactive protein level in predialysis chronic kidney disease patients in southern Nigeria. Ghana Med J., 50(1): 31-38.

13. Kidane D, Chae W, Czochor J et al. (2014): Interplay between DNA repair and inflammation, and the link to cancer. Crit Rev Biochem Mol Biol., 29(2): 116-139.

14. Stoyanova E, Sandoval SB, Zuniga LA et al. (2010): Oxidative DNA damage in chronic renal failure patients. Nephrol. Dial. Transplant.. 25: 879-885.

15. Ohnishi S, Ma N, Thanan R et al. (2013): DNA damage in inflammation-related carcinogenesis and cancer stem cells. Oxid Med Cell Longev., 4:1-9. 
16. Hooten NN, Ejiogu N, Zonderman AB, Evans MK (2012): Association of oxidative DNA damage and C-reactive protein in women at risk for cardiovascular disease. Arterioscler Thromb Vasc Biol., 32(11):2776-2784.

17. Schupp N, Stopper H, Heidland A (2016): DNA damage in chronic kidney disease: evaluation of clinical biomarkers. Oxid Med Cell Longev., 15(4): 333-345.

18. Hoenich NA, Levin R, Ronco C (2010): Water for haemodialysis and related therapies: recent standards and emerging issues. Blood Purif., 29(2):81-85.

19. Arizono K, Nomura K, Motoyama T et al. (2004): Use of ultrapure dialysate in reduction of chronic inflammation during hemo-dialysis. Blood Purif., 22( 2): 26-29.

20. Moffitt T, Garrett PJ, Hannon-Fletcher M (2014): Oxidative DNA damage is elevated in renal patients undergoing haemodialysis. Open J Prev Med., 4(6):421-428.

21. Roth JM, Restani RG, Goncalves TT et al. (2008): Genotoxicity evaluation in chronic renal patients undergoing hemodialysis and peritoneal dialysis, using the micronucleus test. Genet Mol Res., 7(2):433-443

22. Zachara BA, Gromadzinska J, Palus J et al. (2011): The effect of selenium supplementation in the prevention of DNA damage in white blood cells of hemodialyzed patients: a pilot study. Biol. Trace Elem. Res., 142:274-283.

23. Aykanat B, Cakmak-Demircigil G, Fidan K et al. (2011): Basal damage and oxidative
DNA damage in children with chronic kidney disease measured by use of the comet assay. Mutat. Res., 725: 22-28.

24. Kobras K, Schupp N, Nehrlich $\mathrm{K}$ et al. (2006): Relation between different treatment modalities and genomic damage of end-stage renal failure patients. Kidney Blood Press Res., 29:10-17.

25. Corredor Z, Rodriguez-Ribera L, Silva I et al. (2016): Levels of DNA damage in peripheral blood lymphocytes of patients undergoing standard hemodialysis vs on-line hemodiafiltration: A comet assay investigation. Mutat Res Genet Toxicol Environ Mutagen., 808:1-7.

26. Akchurin OM, Kaskel F (2015): Update on inflammation in chronic kidney disease. Blood Purif., 39:84-92.

27. Saland JM, Pierce CB, Mitsnefes MM et al. (2010): Dyslipidemia in children with chronic Kidney. Kidney Int., 78:1154-1163.

28. Wilson AC, Schneider MF, Cox C et al. (2011): Prevalence and correlates of multiple cardiovascular risk factors in children with chronic kidney disease. Clin J Am Soc Nephrol., 6:27592765.

29. Parekh RS, Carroll CE, Wolfe RA et al. (2002): Cardiovascular mortality in children and young adults with end-stage kidney disease. J Pediatr., 141:191-197.

30. Mitsnefes MM (2012): Cardio-vascular disease in children with chronic kidney disease. J Am Soc Nephrol., 23: 578-585. 